\title{
Comparison of Open and Closed Stance Forehand Strokes among Intermediate Tennis Players
}

\author{
Tajul Arifin Muhamad \\ 1Departemant Sport Management, Faculty of Education, \\ Universiti Kebangsaan Malaysia, Kajang 43600, Malaysia \\ Email: tajul.a@ukm.edu.my \\ Fatemeh Golestani (Corresponding author) \\ 1Departemant Sport Management, Faculty of Education, \\ Universiti Kebangsaan Malaysia, Kajang 43600, Malaysia \\ 2Enghelab Tennis Club, Enghelab Sport Complex, Tehran, Iran \\ Email: Golestani2015@gmail.com \\ Mohd Radzani Abd Razak \\ Departemant Sport Management, Faculty of Education, \\ Universiti Kebangsaan Malaysia, Kajang 43600, Malaysia \\ Email: jingga@ukm.edu.my
}

Received: 18-10- 2015

Accepted: 20-12- 2015

Published: 08-01- 2016

doi:10.7575/aiac.ijkss.v.4n.1p.26

\begin{abstract}
Background: Nowadays tennis is becoming faster and players are able to hit powerful from virtually anywhere on the tennis court. Training programmers and effective planning will help in designing safe, effective, and productive programs designed to help optimize the tennis performance of players. Objective: This research examine the effectiveness of open and closed stance forehand strokes in terms of percentage of success, accuracy and also to investigate whether there is a relation between level of accuracy and the choice of forehand strokes used by tennis player. Method: Participants were divided into two groups, namely, male and female who learned forehand strokes for one month. The participants were tested by using a two skill test for percentage of success and level of accuracy. Result: Founding showed that the closed stance forehand stroke has far better percentage of success and accuracy among the intermediate tennis players, but the difference was not significant. In addition, male players showed more accuracy and success in this research. And also accuracy did not have any influence to choice of forehand stroke among the intermediate tennis players. Conclusion: This research could improve the training protocol design for teaching the closed stance and open stance strokes.
\end{abstract}

Keywords: Forehand stroke, open stance, closed stance, tennis accuracy, percentage of success

\section{Introduction}

Tennis is a popular sport played throughout the world. It is estimated that about 75 million people play tennis regularly. Tennis is a sport usually played between two players (singles) or between two teams of two players each (doubles)(Ireland, Degens, Maffulli, \& Rittweger, 2015). Each player uses a racket that is strung to strike a hollow rubber ball covered with felt over a net and into the opponent's court (Brown \& Soulier, 2013). The object of the game is to play the ball in such a way that the opponent is not able to play a good return. Tennis is an Olympic sport and is played at all levels of society at all ages. The sport can be played by anyone who can hold a racket, including people in wheelchairs (Bahamonde \& Knudson, 2003; Duane, 1991; Sandamas, 2013).

Forehand strokes is the most important shot in a player's arsenal after the serve, (Matsuzaki, 2004; Roetert \& Groppel, 2001). Rotation of both lower body and the upper body has been described as a significant source of power in the forehand stroke. The energy is transferred upward from the legs to the pelvis, through the trunk to the arm and then to the racket. In the kinetic chain of the lower body, the knee joint is regarded as the "critical middle link" in the proximal transfer of force(Whiting \& Zernicke, 2008). The rotation of trunk and the pelvis involves torsional forces in the lower body, not only during the forward swing but also during the follow -through in which this rotational energy is being dissipated. Research into the lower limb kinetics of the closed stance (CS) forehand has shown that a leg drive is essential to create high axial hip rotational torques to aid trunk rotation (Iino and Kojima, 2003). In study by Bryant (2011) and Gallwey (2010) stated the recovery time is quicker in the open stance because a player is already facing the net in the ready position after striking the ball, 
as opposed to the closed stance in which the weight of the body is moving forward from the step in and then must take the extra step back to the ready position. Only sagittal plane knee moments have been described in these prior studies (Fleisig, Nicholls, Elliott, \& Escamilla, 2003; Roetert \& Groppel, 2001).

\subsection{Closed stance forehand}

The forehand stroke in tennis has long been qualified and performed as one style. This style is identified by three names: the closed, squared, or sideways stance forehand. The closed stance forehand brings up the situation during and previous to contact with the ball. A stripe sketched from the back foot to the front foot should run equivalent to the planned path of the ball (Elliott, Reid, \& Crespo, 2003).

\subsection{Open stance forehand}

The alternative option to the closed stance forehand is the open stance forehand. This method has become essential because of the absolute power of the game as played today. The situation of the body in the open stance forehand is such that the hips and shoulders are equivalent or "open" to the net (Alizadehkhaiyat \& Frostick, 2015). The right foot (for right-hand dominant players) is placed at the back as the player progresses sideways and gets ready for the ball as the shoulders and hips are turned in anticipation of the approaching ball (Gallwey, 2010). The open stance forehand has been explained insufficiently in early literature and has been noted as the incorrect thing to do if described at all. References stated that if the feet are parallel to the net when a player hits the ball, then after that they are in an incorrect position (Roetert \& Groppel, 2001). Despite this, there is very little published data concerning three-dimensional tennis biomechanics and almost nothing related to lower limb kinetics of the forehand. This study generally intends to examine and compare the effectiveness of the open and closed stance forehand strokes, and to determine whether there is a relationship between the open and closed stance forehand in terms of percentage of success and accuracy level. This study also specifically aims at measuring and analysing the percentage of success and the level of accuracy using the open and closed stance forehand among tennis players. Some previous research studies in the literature have usually involved investigating the effects of tennis strokes on different parts of the body. Some studies have also examined the analysis of tennis strokes with regard to percentage of success and accuracy level among tennis players. However, there is a lack of studies concerning the relationship between different tennis strokes and stance positions(Roetert \& Groppel, 2001).

\section{Methodology}

The population of the study consisted of all intermediate tennis players ranging from 18 to 25 years old who were learning the sport of tennis in Enghelab Tennis Club located in Tehran, Iran. From the research population, sixty-four players were selected as the sample for this study. The framework for this study is described in Figure 1. The participants consisted of 32 males and 32 females. All the participants were the official members of the Enghelab Tennis Club, Tehran. The participants underwent a training programme for four weeks, three times a week for 90 minutes per session. After the training programme, the participants were divided into two groups, namely an 'open stance forehand group' and a 'closed stance forehand group'. The criterion for this classification was their performance in hitting open and closed stance forehand strokes during the training programme. Each research group consisted of 32 players (Mackie, 2013)

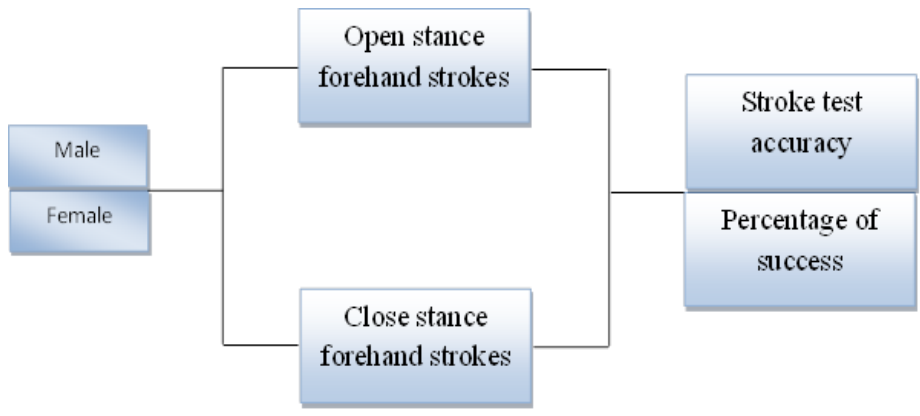

Figure 1. Framework

The tennis players were required to hit $\mathrm{AC}$ and DL strokes from the baseline with their preferred technique and to hit balls from the coach (ball feeder). It was important for the coach to master the feeding technique and procedure, so the feeder can provide challenging situations through precise and consistent feeding, and also to provide more repetition of the specific situations for testing the percentage of success and the level of accuracy regarding the open and close stance forehand position. The coach was required to stand exactly at the location required by the situation. The coach could modify this position in order to perform a progression, but progressively move back into the proper position. Basically the coach was feeding the balls at the ground -strike zone. This is the area of the tennis court where nearly all the play takes place in order to win a point. It requires patience, planning, vision and depth. Players need to be patient in this zone. These represent the planning based on the move forward, or for a put-away shot, which should be the player's ultimate goal. 


\subsection{Testing Procedure}

The study investigated differences in the open stance forehand and closed stance forehand strokes when hit and down the line (DL) and across court (AC). Each participant hit (20) open stance or closed stance forehand strokes as if they were playing a real tennis match (powerful and without effect forehand strokes), trying to hit four pre-established targets. The player had been commanded to take just one ball at the same time with the objective of keeping a (5) to (7) second interval between each open stance or closed stance forehand, as it occur in a real matches. Three sessions were designed for each group, namely, open stance, closed stance and stroke and the total score of each player was recorded. According to the difficulty le vel of task the scoring record of each target was defined, as follows: Three points on the desired target, two points in the intermediate area and 1 point if the third area is hit. Zero points given for not hitting the areas, at the net.

According to Figure 2, each side of the court was split into three parts. Depending on the number of forehand strokes hitting the target (area), participate could score 0 to 3 points. The tennis player had to hit forehand strokes five times for each of the targets. The data was considered as a categorical variable so a test for goodness of fit was performed between an observed sample and theoretical distribution and a contingency test for independence between two or more variables.

Each tennis player from the open stance forehand group and the closed stance forehand had to stand behind the baseline of the tennis court, so they could receive successful shots to their forehand sides. The player hit five forehand strokes at each of the AI, FV, FL, and AV targets. The coach (feeder) who stood on the opposite side of the player side consequently grabbed five balls and could speed up the rhythm and provide a better flow for the test by standing exactly at the location required by the situation. The feeder should preferably use a continental grip to allow any type of feed when creating a specific situation, although the feeder could use the grip necessary to provide the proper shot. The feeder was able to feed from any stroke without looking at the ball, so the feeder could maintain eye contact with the students.

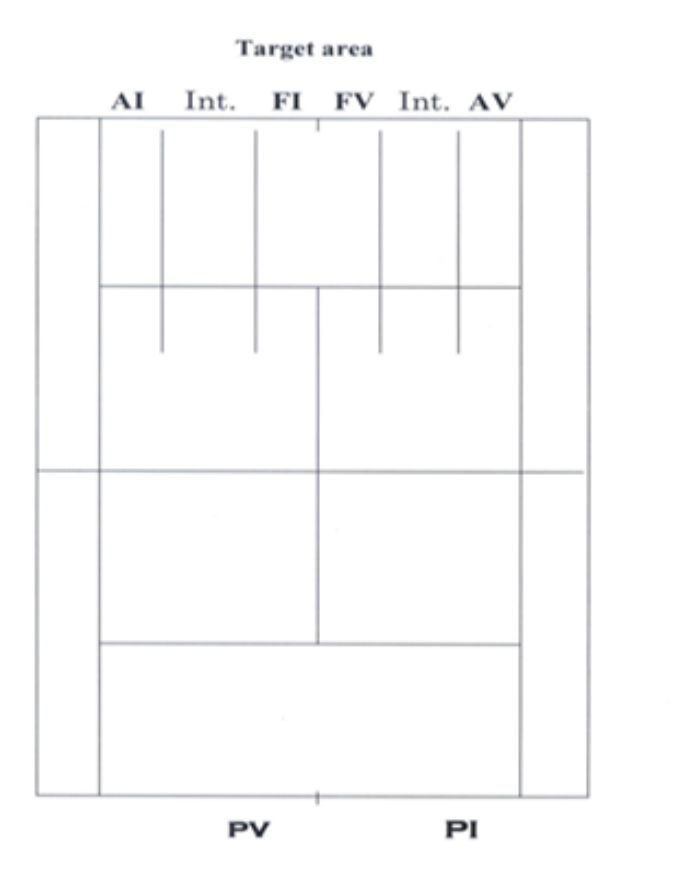

Figure 2. Tennis court

\subsection{Data analysis}

In order to compare open stance and closed stance strokes among intermediate tennis players using SPSS. The results of the statistical analysis are reported with regard to independent T- tests using SPSS version 21. These included descriptive statistics for age, weight and height of the respondents. The effectiveness of both the open stance and closed stance strokes will be measured in terms of the rate of success and accuracy.

\section{Results}

According to Table 4-1 in both groups, including open and closed stance, the age of the respondents was between 18 to 25 and the average of age in these two groups was $M=21.71$ and $M=21.34$ respectively. The difference between these two groups in terms of age was not statistically different. The average of the height in the open stance group was $\mathrm{M}=170.97$ and in the closed stance group it was 169.19 which was also not significantly different. The minimum respondent age in both groups was same and the average weight in the open group was $M=66.97$ which was not 
statistically different from the closed stance group at $M=67.72$. These results confirmed that both groups were homogenised (Table 1 and Table 2).

Table 1. Descriptive statistics for weight, age and height of tennis players

\begin{tabular}{llllllll}
\hline Learning & & $\mathrm{N}$ & Minimum & Maximum & Mean & SD \\
\hline Open stance & Age & 32 & 18 & 25 & 21.71 & 2.565 \\
& Height & 32 & 159 & 190 & 170.97 & 8.926 \\
& Weight & 32 & 44 & 88 & 66.97 & 9.75 \\
Closed stance & Age & 32 & 18 & 25 & 21.34 & 2.404 \\
& Height & 32 & 150 & 186 & 169.19 & 8.682 \\
& Weight & 32 & 44 & 90 & 67.72 & 11.419 \\
\hline
\end{tabular}

Table 2. Difference between open and closed stance for age, weight and height

\begin{tabular}{lllll}
\hline & $\mathrm{t}$ & $\mathrm{df}$ & $\mathrm{P}$ value & Mean Difference \\
\hline Age & 0.591 & 64 & 0.557 & 0.362 \\
Height & 0.822 & 64 & 0.414 & 1.783 \\
Weight & -0.287 & 64 & 0.775 & -0.748 \\
\hline
\end{tabular}

\subsection{Differentiating Between Males and Females}

To determine the difference between the males and females in terms of percentage of success and accuracy level in both open and closed stances, an independent $t$ test was applied and the results indicated that there was a significant difference between females and males for success in all tests (Table 3 and Table 4). In the open stance forehand group the average of success for females in the first evaluation was $32.94 \pm 6.88$ while for males it was $49.31 \pm 10.75$. In the second evaluation this percentage of success among males increased by $4 \%$, but the success of females reduced by $1 \%$. This difference was still significant in the third assessment in which males had a higher percentage of success at $53.0 \pm 11.22$ compared to females at $36.07 \pm 5.30$.

For the closed stance forehand group the average of success for females in the first evaluation was $40.104 \pm 9.33$ while for males it was $53.95 \pm 11.25$. In the second evaluation this percentage of success among males decreased by $4 \%$ and the female success reduced by $1 \%$. The difference at this stage was significant. In the last assessment, males had a higher percentage of success at $52.5 \pm 10.97$ compared to females at $41.14 \pm 7.44$ (Table 3 ).

Table 3. Mean comparison between male and female for success in both closed and open stance

\begin{tabular}{|c|c|c|c|c|c|c|c|}
\hline & & Gender & $\mathrm{N}$ & Mean & SD & $\mathrm{t}$ & $\mathrm{p}$ value \\
\hline \multirow{6}{*}{ Open stance } & \multirow[t]{2}{*}{ success 1} & Female & 16 & 32.9 & 6.8 & \multirow[t]{2}{*}{-5.287} & \multirow[t]{2}{*}{$<0.05$} \\
\hline & & Male & 16 & 49.3 & 10.7 & & \\
\hline & \multirow[t]{2}{*}{ success 2} & Female & 16 & 31.9 & 9.1 & \multirow[t]{2}{*}{-7.038} & \multirow[t]{2}{*}{$<0.05$} \\
\hline & & Male & 16 & 53.4 & 8.6 & & \\
\hline & \multirow[t]{2}{*}{ success 3} & Female & 16 & 36.0 & 5.3 & \multirow[t]{2}{*}{-5.73} & \multirow[t]{2}{*}{$<0.05$} \\
\hline & & Male & 16 & 53.3 & 11.2 & & \\
\hline \multirow[t]{6}{*}{ Closed stance } & \multirow[t]{2}{*}{ success 1} & Female & 16 & 40.10 & 9.3 & \multirow[t]{2}{*}{-3.79} & \multirow[t]{2}{*}{$<0.05$} \\
\hline & & Male & 16 & 53.9 & 11.2 & & \\
\hline & \multirow[t]{2}{*}{ success 2} & Female & 16 & 39.6 & 8.5 & \multirow[t]{2}{*}{-2.988} & \multirow[t]{2}{*}{$<0.05$} \\
\hline & & Male & 16 & 49.4 & 9.9 & & \\
\hline & \multirow[t]{2}{*}{ success 3} & Female & 16 & 41.1 & 7.4 & \multirow[t]{2}{*}{-3.425} & \multirow[t]{2}{*}{$<0.05$} \\
\hline & & Male & 16 & 52.5 & 10.9 & & \\
\hline
\end{tabular}

In the open stance forehand group the average accuracy of females in the first appraisal was $11.94 \pm 2.13$, while males were $14.29 \pm 1.961$ which was significant at the 0.05 level. The difference between males and females at the next 
assessment was again significant and males had a higher accuracy than females. This difference was still significant in the third assessment in which males maintained a higher accuracy at 15.12 \pm 1.576 compared to females at $12.88 \pm 2.315$.

For the closed stance forehand group the average accuracy of the females in the first evaluation was $12.5 \pm 2.633$ while for the males it was significantly higher at $15.56 \pm 1.548$. In the second evaluation, the accuracy among males was higher than the females. The difference at this stage was significant. In the last stage, still the males at $15.75 \pm 2.38$ showed a higher accuracy than the females at $13.25 \pm 2.543$ (Table 4).

Table 4. Mean comparison between males and females for accuracy in both open and closed stance forehand

\begin{tabular}{|c|c|c|c|c|c|c|c|}
\hline Learning & & Gender & $\mathrm{N}$ & Mean & SD & $\mathrm{t}$ & $\mathrm{P}$ value \\
\hline \multirow{6}{*}{$\begin{array}{l}\text { Open } \\
\text { stance }\end{array}$} & Accuracy1 & $\bar{F}$ & 16 & 11.94 & 2.135 & -3.346 & $<0.05$ \\
\hline & & M & 16 & 14.29 & 1.961 & & \\
\hline & Accuracy 2 & $\mathrm{~F}$ & 16 & 11.82 & 3.264 & -3.55 & $<0.05$ \\
\hline & & M & 16 & 15.12 & 1.996 & & \\
\hline & Accuracy3 & $\mathrm{F}$ & 16 & 12.88 & 2.315 & -3.29 & $<0.05$ \\
\hline & & $\mathrm{M}$ & 16 & 15.12 & 1.576 & & \\
\hline \multirow{5}{*}{$\begin{array}{l}\text { Closed } \\
\text { stance }\end{array}$} & Accuracy1 & $\mathrm{F}$ & 16 & 12.52 & 2.633 & -4.011 & $<0.05$ \\
\hline & & M & 16 & 15.56 & 1.548 & & \\
\hline & Accuracy2 & $\mathrm{F}$ & 16 & 12.63 & 2.187 & -3.468 & $<0.05$ \\
\hline & & M & 16 & 14.94 & 1.526 & & \\
\hline & Accuracy3 & $\mathrm{F}$ & 16 & 13.25 & 2.543 & -2.871 & $<0.05$ \\
\hline
\end{tabular}

\subsection{Difference Between Open and Closed Stance for Total Success and Accuracy}

The total success and total accuracy scores were calculated based on the average of three scores and were applied for comparison between the open and closed stance groups. According to the normal distribution of both variables, an independent sample $t$ test was applied to study the difference between the two groups for total success and total accuracy. The results of the $t$ test revealed that there were no significant differences between open and closed stance forehand for total accuracy and total success as shown in Table 5.

Table 5. Mean comparison between open and closed stance for accuracy

\begin{tabular}{lllllll}
\hline & Learning & $\mathrm{N}$ & Mean & $\mathrm{SD}$ & $\mathrm{t}$ & $\mathrm{P}$ value \\
\hline \multirow{2}{*}{ Total accuracy } & Open stance & 32 & 13.5294 & 2.19445 & -1.077 & 0.286 \\
& Closed stance & 32 & 14.1042 & 2.13763 & & \\
\hline \multirow{2}{*}{ Total success } & Open stance & 32 & 42.8431 & 11.73642 & -1.269 & 0.209 \\
& Closed stance & 32 & 46.25 & 9.93608 & & \\
\hline
\end{tabular}

\subsection{Differentiating Between Males and Females}

To determine the difference between male and female in terms of percentage of success and accuracy level in both the open and closed stances, an independent $t$ test was applied and the results showed that there was a significant difference between females and males for total success and total accuracy (Table 6). In the open stance, forehand group the average of success for females was $33.66 \pm 5.71$ while for males it was $52.02 \pm 8.50$. This difference was significant at the 0.05 level. In the closed stance forehand group a significant difference was also observed for total success among females $40.31 \pm 7.10$ and males $52.18 \pm 8$.85. In the closed stance, forehand group the total accuracy for females was $12.21 \pm 2.633$, which was significantly lower than for males at $14.84 \pm 1.30$.

Table 6. Mean comparison between gender for total success and accuracy

\begin{tabular}{llllllll}
\hline \multirow{3}{*}{ Open stance } & Learning & Gender & $\mathrm{N}$ & Mean & SD & $\mathrm{t}$ & $\mathrm{p}$ value \\
& Total accuracy & Female & 16 & 12.2157 & 2.13418 & -4.328 & $<0.05$ \\
& & Male & 16 & 14.8431 & 1.30766 & & \\
Total success & Female & 16 & 33.6601 & 5.71324 & -7.394 & $<0.05$ \\
& & Male & 16 & 52.0261 & 8.5005 & & \\
Closed stance & Total accuracy & Female & 16 & 12.7917 & 1.95458 & -4.372 & $<0.05$ \\
& & Male & 16 & 15.4167 & 1.39576 & & \\
& \multirow{2}{*}{ Total success } & Female & 16 & 40.3125 & 7.10002 & -4.185 & $<0.05$ \\
& & Male & 16 & 52.1875 & 8.85519 & & \\
\hline
\end{tabular}




\section{Discussion}

The current research intends to examine and compare the effectiveness of the open and closed stance Tennis forehand strokes, and also determine whether there is a relationship between the open and closed stance forehand in terms of percentage of success and accuracy level. This study also specifically aimed at measuring and analysing the percentage of success and the level of accuracy using the open and closed stance forehand among tennis players. Some previous research studies in the literature have usually involved investigating the effects of tennis strokes on different parts of the body. Some studies have also examined the analysis of tennis strokes with regard to percentage of success and accuracy level among tennis players (Larson \& Guggenheimer, 2013; Stare, Žibrat, \& Filipčič, 2015; Vaverka \& Cernosek, 2013). However, there is a lack of research concerning the relationship between different tennis strokes and stance positions (Erman, Şahan, \& Küçükkaya, 2013; Reid, Elliott, \& Crespo, 2013)

Muhammad et al in 2011 compares the effectiveness of single and double handed backhand strokes in terms of percentage of success, accuracy, and also to determine whether there is an association between their agility level and the of choice of strokes used. In order to evaluate different 16 tennis players ranging 16- 25 year from National Tennis Centre (NTC) and Bukit Jalil Sports School volunteered to participate in the research. Samples were tested for agility and a two-item skill test for accuracy and percentage of success. They found that double handed backhand have better result and but the difference was not significant and also result shows agility did not have any effectiveness on the choice of backhand strokes (Muhamad, Rashid, Razak, \& Salamuddin, 2011).

The first objective of this research was to study the level of accuracy and success of the participants in both the open and closed stance groups in three stages. The methodology of this study included, testing procedure (number of players and group), demographic data (age, weight, height), test of agility (successes and accuracy), and statistical analysis. In this study the participants (ranging from 18 to 25 years old) were 32 males and 32 females. The participants were categorised into two groups, namely 'open stance forehand group' and 'closed stance forehand group'. Then, the mean, the percentage of success, the level of accuracy, and standard deviation of the forehand stroke performance of each player was calculated. The result of three testing steps showed that the closed stance forehand was more accurate than the open stance forehand. This was probably due to the correct forehand techniques used by tennis players in the closed stance forehand group or probably it was an easier method to handle high and fast balls. The level of success was considered between both the closed stance forehand group and the open stance forehand group. Overall, the level of success among the closed stance group was greater than the open stance forehand group. In other words, the closed stance forehand group had a better percentage of success for the intermediate tennis players. The average score for the accuracy and percentage of success for the closed stance forehand group was higher than for the open stance forehand group. This was probably due to the weight and previous experience of the players, which was slightly higher for that group. Therefore, the use of better forehand techniques does not only give more tactical options but also more efficient strokes. The result of this research is similar to previous research conducted by Akram (2011) who considered the one handed backhand and two handed backhand in tennis players (Muhamad et al., 2011).

\section{Conclusion}

Nowadays tennis is becoming faster and players are able to hit powerful from virtually anywhere on the tennis court. Training programmers and effective planning will help in designing safe, effective, and productive programmes designed to help optimise the tennis performance of players. As a result, players need to train their bodies to meet these increasing demands. Therefore, the researcher feels that future study should examine more strokes and the accuracy level of the tennis players to improve the standard of the game. This information could improve the training protocol design for teaching the closed stance and open stance strokes.

\section{Acknowledgement}

The authors are grateful for the assistance and financial support provided by the Universiti Kebangsaan Malaysia.

\section{References}

Alizadehkhaiyat, O., \& Frostick, S. P. (2015). Electromyographic assessment of forearm muscle function in tennis players with and without Lateral Epicondylitis. Journal of Electromyography and Kinesiology, 25(6), 876-886.

Bahamonde, R., \& Knudson, D. (2003). Kinetics of the upper extremity in the open and square stance tennis forehand. Journal of Science and Medicine in Sport, 6(1), 88-101.

Brown, J., \& Soulier, C. (2013). Tennis: Steps to success: Human kinetics.

Duane, V. (1991). Factors affecting force loading on the hand in the tennis forehand. J Sports Med Phys Fitness, 31, 527-531.

Elliott, B., Reid, M., \& Crespo, M. (2003). ITF biomechanics of advanced tennis: International Tennis Federation.

Erman, K. A., Şahan, A., \& Küçükkaya, A. (2013). The effect of one and two-handed backhand strokes on hand-eye coordination in tennis. Procedia-Social and Behavioral Sciences, 93, 1800-1804. 
Fleisig, G., Nicholls, R., Elliott, B., \& Escamilla, R. (2003). Tennis: Kinematics used by world class tennis players to produce high-velocity serves. Sports Biomechanics, 2(1), 51-64.

Gallwey, W. T. (2010). The inner game of tennis: The classic guide to the mental side of peak performance. Random House Trade Paperbacks: Random House.

Iino, Y., \& Kojima, T. (2003). Role of knee flexion and extension for rotating the trunk in a tennis forehand stroke. Journal of Human Movement Studies, 45(2), 133-152.

Ireland, A., Degens, H., Maffulli, N., \& Rittweger, J. (2015). Tennis Service Stroke Benefits Humerus Bone: Is Torsion the Cause? Calcified tissue international, 1-6.

Larson, E. J., \& Guggenheimer, J. D. (2013). The effects of scaling tennis equipment on the forehand groundstroke performance of children. Journal of sports science \& medicine, 12(2), 323.

Mackie, D. (2013). The Effects of Gender on the Work to Rest Ratio of Elite Level Tennis Players. Cardiff Metropolitan University, http://hdl.handle.net/10369/5032.

Matsuzaki, C. (2004). Tennis fundamentals: Human Kinetics.

Muhamad, T. A., Rashid, A. A., Razak, M. R. A., \& Salamuddin, N. (2011). A comparative study of backhand strokes in tennis among national tennis players in Malaysia. Procedia-Social and Behavioral Sciences, 15, 3495-3499.

Reid, M., Elliott, B., \& Crespo, M. (2013). Mechanics and learning practices associated with the tennis forehand: a review. Journal of sports science \& medicine, 12(2), 225.

Roetert, P., \& Groppel, J. L. (2001). World-class tennis technique: Human Kinetics.

Sandamas, P. (2013). Knee joint loading in the open and square stance tennis forehands. http://hdl.handle.net/123456789/41756, Master's thesis, University of Jyväskylä.

Stare, M., Žibrat, U., \& Filipčič, A. (2015). STROKE EFFECTIVENESS IN PROFESSIONAL AND JUNIOR TENNIS. Kinesiologia Slovenica, 21(2).

Vaverka, F., \& Cernosek, M. (2013). Association between body height and serve speed in elite tennis players. Sports Biomechanics, 12(1), 30-37.

Whiting, W. C., \& Zernicke, R. F. (2008). Biomechanics of musculoskeletal injury: Human Kinetics. 